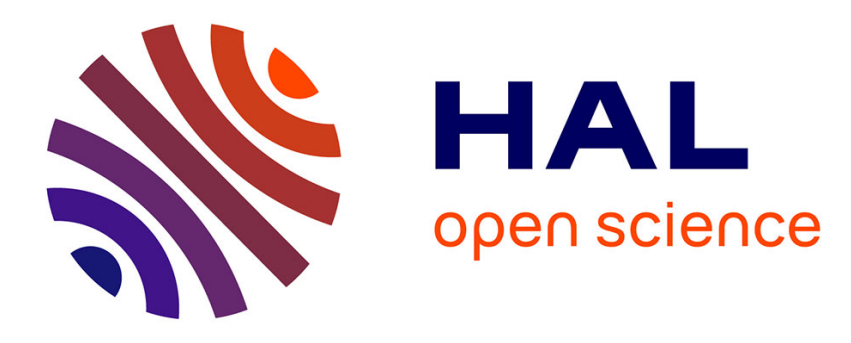

\title{
LCVD of aluminium stripes obtained by pyrolysis of TMAA and TMA
}

V. Shanov, C. Popov, B. Ivanov

\section{To cite this version:}

V. Shanov, C. Popov, B. Ivanov. LCVD of aluminium stripes obtained by pyrolysis of TMAA and TMA. Journal de Physique IV Proceedings, 1993, 03 (C3), pp.C3-255-C3-260. 10.1051/jp4:1993334 . jpa-00251391

\section{HAL Id: jpa-00251391 https://hal.science/jpa-00251391}

Submitted on 1 Jan 1993

HAL is a multi-disciplinary open access archive for the deposit and dissemination of scientific research documents, whether they are published or not. The documents may come from teaching and research institutions in France or abroad, or from public or private research centers.
L'archive ouverte pluridisciplinaire HAL, est destinée au dépôt et à la diffusion de documents scientifiques de niveau recherche, publiés ou non, émanant des établissements d'enseignement et de recherche français ou étrangers, des laboratoires publics ou privés. 


\title{
LCVD of aluminium stripes obtained by pyrolysis of TMAA and TMA
}

\author{
V. SHANOV, C. POPOV and B. IVANOV
}

Technological University of Sofia, Dept. of Semiconductors, 8 Kliment Ohridski St., 1756 Sofia, Bulgaria

\begin{abstract}
Maskless patterning of aluminium has been achieved by using visible light from a copper bromide vapor laser for pyrolytic decomposition of trimethylaluminium (TMA) and trimethylamine alane (TMAA). A silicon monocrystalline wafer was used as a substrate. The deposition was carried out at different process parameters (partial pressure of the precursors, laser power and scanning speed). The analysis of the resultant stripes included scanning electron microscopy, Auger electron spectroscopy, Talystep and electrical resistance measurements. The crystalline structure of the layers showed well-defined grains for both precursors. The Auger electron spectra indicated pure aluminium layers with small quantities of oxygen and carbon for stripes deposited from TMAA while those obtained from TMA were more contaminated. The difference in the layers composition for the used precursors resulted in their resistivity values. The low resistivities of aluminium stripes deposited from TMAA (up to $4.0 \mu \Omega$.cm) makes it promising precursor for metalization with aluminium and especially for chemical vapor deposition enhanced with pulsed visible laser.
\end{abstract}

\section{Introduction}

Metal organic chemical vapor deposition (MOCVD) has become a successful competitor to the classical sputtering method for aluminium deposition [1]. New approach in this technology holds out the possibility of using laser beam which is able to draw micron-sized metal features. However for laser chemical vapor deposition (LCVD) to become widely applicable, the precursors should cleanly decompose to high-purity metal, and to be easy to handle and volatile. Trialkyl aluminium compounds are widely used precursors for MOCVD of aluminium and compound semiconductors [2,3] and for LCVD of Al [4]. These aluminium alkyls have a disadvantage which concerns the incorporation of carbon in the growing layers. As an alternative to the use of trialkyl aluminium compounds recently new aluminium precursor trimethylamine alane (TMAA) was reported. It is excellent aluminium source for epitaxial growing of high quality III-V compounds [5-7] and for deposition of pure metal for microelectronic applications [8-11]. TMAA is an exciting source for LCVD of aluminium although this issue is treated in a fewer papers using $\mathrm{cw}$ visible laser $\left(\mathrm{Ar}^{+}\right)$[12]. This precursor offers some advantages over the common alkyl aluminium sources of being less air sensitive, having simple decomposition pathway and decomposing at temperatures below $1200 \mathrm{C}$. TMAA has a room temperature vapor pressure of 1 Torr which affords high deposition rates without heating the source or transfer lines. Layers of III-V compounds and aluminium grown using TMAA showed greatly reduced levels of carbon and oxygen contamination [5,7-10,12]. This is due to the absence of direct Al-C bond in its molecule, relatively weak donor-acceptor bond between $\mathrm{Al}$ and $\mathrm{N}$ and simple decomposition pathway [9-12]. From the other side oxygen contamination is suppressed by the formation of involatile $\mathrm{Al}-\mathrm{OH}$ species and by the high surface atomic hydrogen concentration.

In our previous works we faced the described disadvantages of using TMA as a precursor for LCVD of aluminium stripes [13-15]. This has motivated our research into application of TMAA for pyrolytic laser deposition of aluminium by pulsed visible (copper vapor) laser. Such laser offers high repetition rate and tremendous power flux for the time of a single pulse (several 
hundred $\mathrm{GW} / \mathrm{m}^{2}$ ) [16]. In the present work we tried to compare both precursors (TMA and TMAA) for LCVD of aluminium.

2. Experimental

TMAA was synthesized according to the published procedures from trimethylamine hydrochloride and lithium aluminium hydride in diethyl ether [17-19]. It was purified by vacuum sublimation into a cold trap and handled under a dry Ar atmosphere. The infrared spectrum and the melting point agreed with those in the literature [17-19].

The experimental set-up for LCVD of aluminium is given on Fig.1.

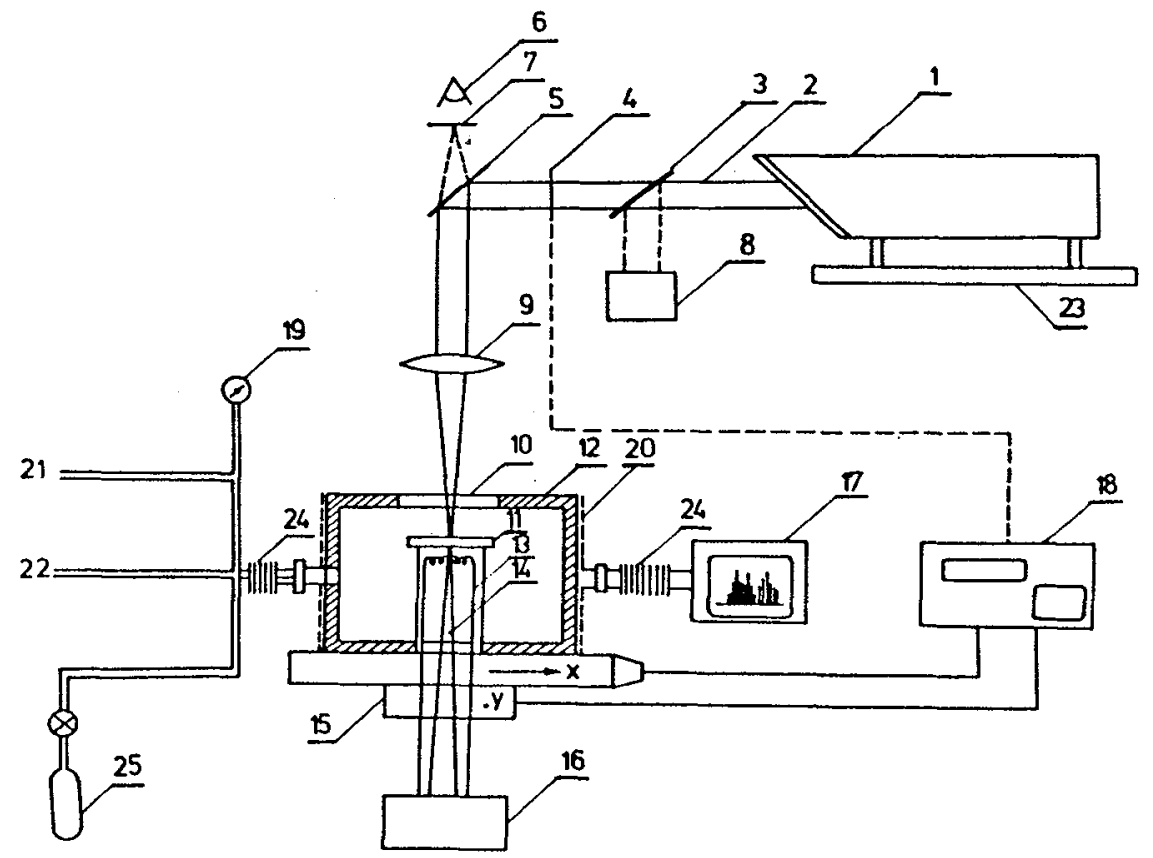

Fig.1. Schematic of the experimental set-up for LCVD

1 - pulsed visible laser; 2 - laser beam; 3 - beam splitter; 4 - optical shutter; 5 - mirror; 6 observer; 7 - optical filter; 8 - power meter; 9 - lens; 10 - quartz window; 11 - wafer holder; 12 cell; 13 - heater; 14 - thermocouple; 15 - stepping stage; 16 - temperature control unit; 17 - mass spectrometer; 18 - computer control unit; 19 - pressure gauge; 20 - heating tape; 21 turbomolecular pump; 22 - gas supply; 23 - granite table; 24 - flexible vacuum connection; 25 metalorganic precursor

The deposition of aluminium stripes in closed reaction cell was carried out by pyrolytic LCVD using a focused beam (up to $130 \mathrm{~mm}$ ) of copper bromide vapor laser (for TMAA) and copper vapor laser (for TMA). Silicon monocrystalline wafers (111) were used as substrates. The experimental steps for direct writing of aluminium stripes were described in details elsewhere [13]. The basic process parameters were varied within reasonable limits determined by the technical capabilities of the equipment and by our previous experimental knowledge. The scanning speed was varied from 10 to $400 \mathrm{~mm} / \mathrm{s}$, the laser power between 0.8 and $2 \mathrm{~W}$ and the partial pressure of the precursors from 0.5 to $10 \mathrm{mbar}$ (for TMA) and from 0.1 to $1 \mathrm{mbar}$ (for TMAA). The width of the stripes obtained was evaluated with a light microscope and their height and profile were measured by Talystep. The electrical resistance was measured with twopoint positioner connected with digital ohmmeter. The morphology of the layers was investigated by scanning electron microscopy (SEM) and the element composition via Auger electron spectroscopy (AES). 


\section{Results and discussion}

The profile of the deposited material approximately follows the laser beam power distribution. Careful evaluation of the geometric parameters was necessary for the further calculation of the resistivity. As shown on Fig. 2 and Fig. 3 the height of the stripes deposited from TMA and TMAA decreases with increase in the scanning speed. This is an expected effect due to the decrease in laser exposure time and surface temperature [20]. Higher laser power results in increase of the stripes height due to the rise of surface temperature.
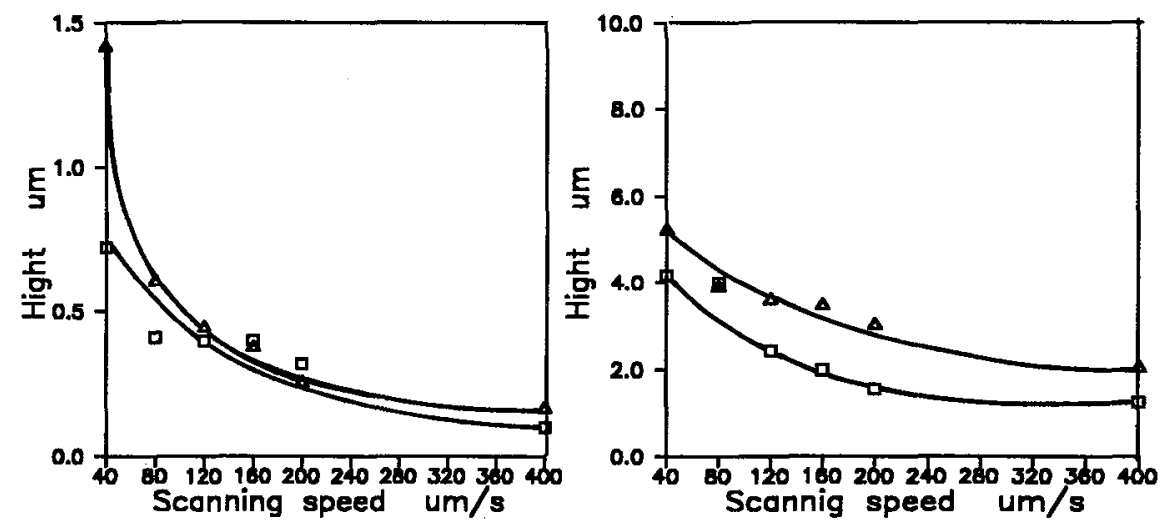

Fig 2 Average stripes height as a function of scanning speed at 1 mbar TMA $\square-0.8 \mathrm{~W} \Delta-1.6 \mathrm{~W}$

Fig 3 Average stripes height as a function of scanning speed at 1 mbar TMAA

$$
\square-1.3 \mathrm{~W} \quad \Delta-1.8 \mathrm{~W}
$$

The same behavior was observed for the width of the lines deposited from TMA - Fig. 4. This parameter was not so sensitive when changing the scanning speed in the case of TMAA - Fig.5.

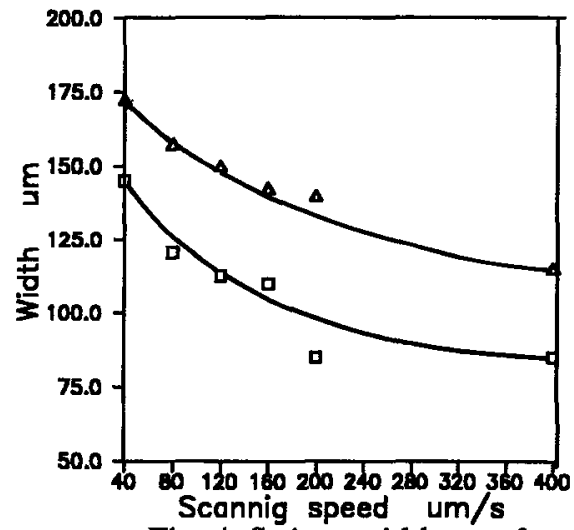

Fig. 4. Stripes width as a function of scanning speed at 1 mbar TMA

$$
\Delta-1.6 \mathrm{~W} \quad \square-0.8 \mathrm{~W}
$$

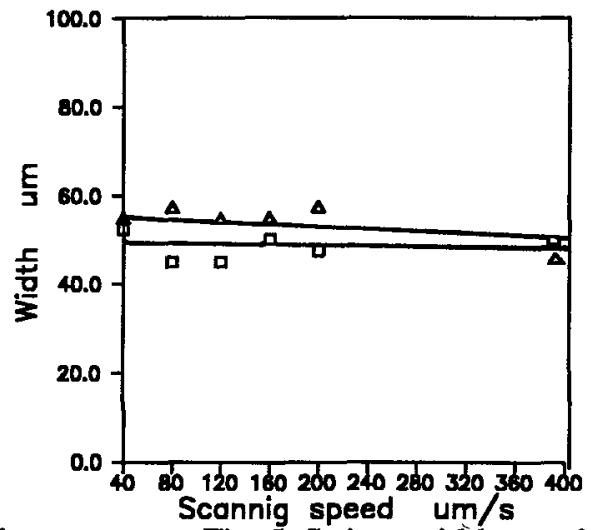

Fig. 5. Stripes width as a function of scanning speed at 1 mbar TMAA

$$
\Delta-1.8 \mathrm{~W} \square-1.3 \mathrm{~W}
$$

The decomposition temperature of TMAA is rather low (approximately $1000 \mathrm{C}$ ) and probably the surface temperature is above this value for the whole range of scanning speeds used in this work. Another point of view for explanation of Fig.5 could be based on the model given by Bauerle [21]. According to this work the width of the deposited line does not change substantially when varying the surface temperature at lower activation energies. If we consider the reported activation energy for Al growth from TMAA - $17.8 \mathrm{kcal} / \mathrm{mol}$ [11] as relatively low 
value then we can apply Bauerle's model. It could explain the width behavior when changing the scanning speed.

The morphology of the deposited aluminium from TMA and TMAA shows well-defined grains (Fig.6) which are more typical for photolytic deposition of metals [22,23]. The grains size depends on the process parameters such as scanning speed, partial pressure of the precursor and laser power. This type of morphology most probably originates from the pulsed time structure of the light source in which the power flux to the substrate for the time of single pulse is several hundreds $\mathrm{GW} / \mathrm{m}^{2}$. This may cause an increase in supersaturation and a high nucleation rate which favours the granular structure. Similar structure with considerable surface roughness was observed for CVD [8] and LCVD [12] of aluminium using TMAA. The size of the grains decreases from the center of the stripes to the edges. This distribution suggests different nuciediion condiiions which are caused by ciifiereni suriace iemperaiures. Folifowing ine Gaussian distribution of laser beam intensity the surface temperature in the center of the spot is higher compared to that at the edges. This effect causes increase of the grains size in the center of the stripes. Secondary melting of aluminium and recrystallization in the central zone of the stripes is not excluded. The size of the grains decreases with the increase of the scanning speed as a result of decrease in the surface temperature (Fig.6 (a) and 6 (c) for TMA and Fig.6 (b) and 6 (d) for TMAA). A new trend in morphology could be recognised when TMAA was used at higher laser power - a dip in the middle of the stripe occurs. This "volcano" effect could be caused by different reasons discussed in details by Moylan et al.[24].
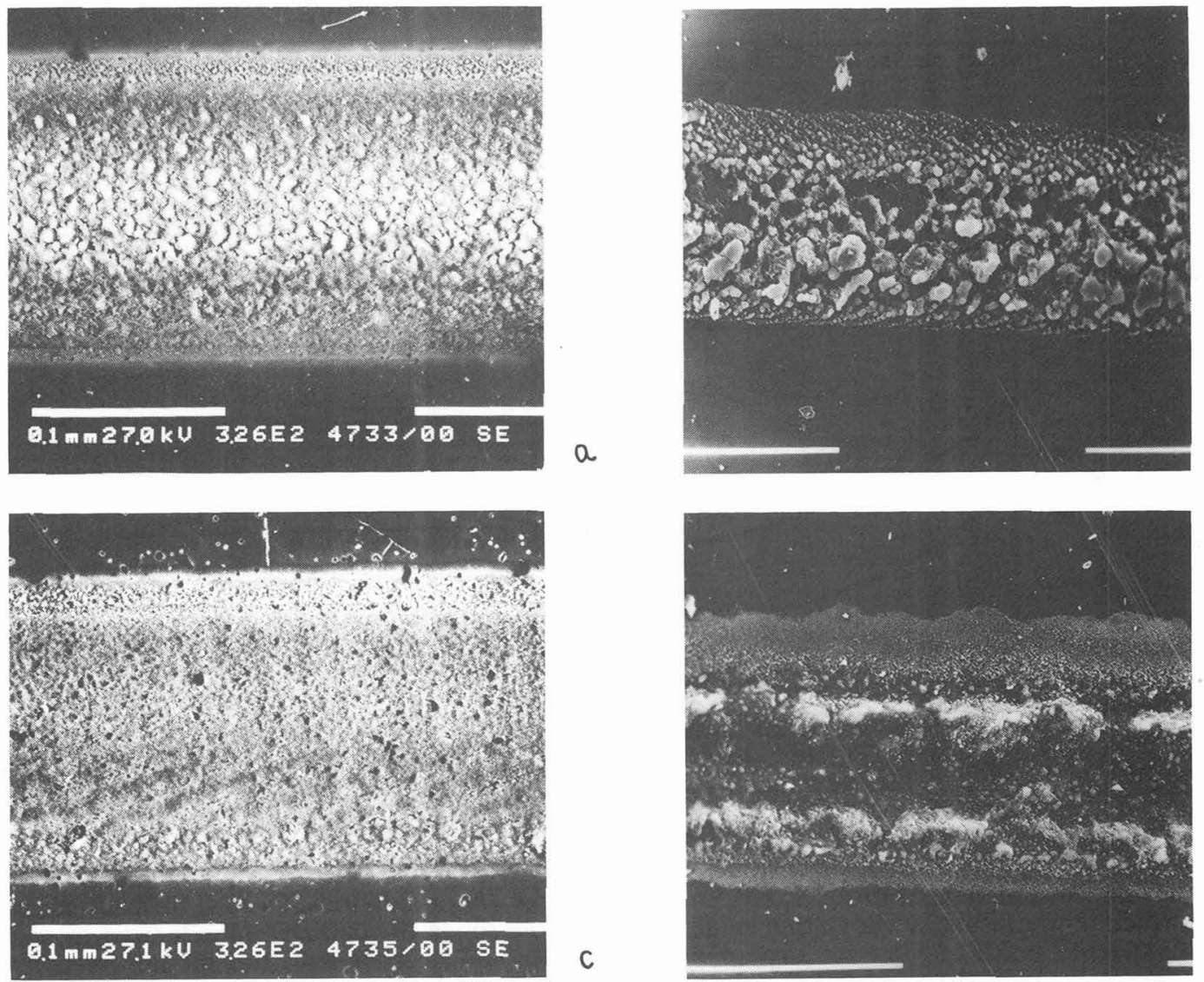

Fig.6 Scanning electron micrographs of aluminium stripes

(a) TMA pressure $1 \mathrm{mbar}$, scanning speed $40 \mu \mathrm{m} / \mathrm{s}$, laser power $0.8 \mathrm{~W}$

(b) TMAA pressure $0.1 \mathrm{mbar}$, scanning speed $10 \mu \mathrm{m} / \mathrm{s}$, laser power $1.3 \mathrm{~W} ; \mathrm{X} 440$

(c) TMA pressure $1 \mathrm{mbar}$, scanning speed $120 \mu \mathrm{m} / \mathrm{s}$, laser power $0.8 \mathrm{~W}$

(d) TMAA pressure $0.1 \mathrm{mbar}$, scanning speed $60 \mu \mathrm{m} / \mathrm{s}$, laser power $1.3 \mathrm{~W} ; \mathrm{X} 440$ 
The element analysis of the deposits from TMA and TMAA were obtained by AES and the depth profiles of the basic elements (aluminium, carbon, oxygen and silicon) are shown on Fig.7 (a) and (b).
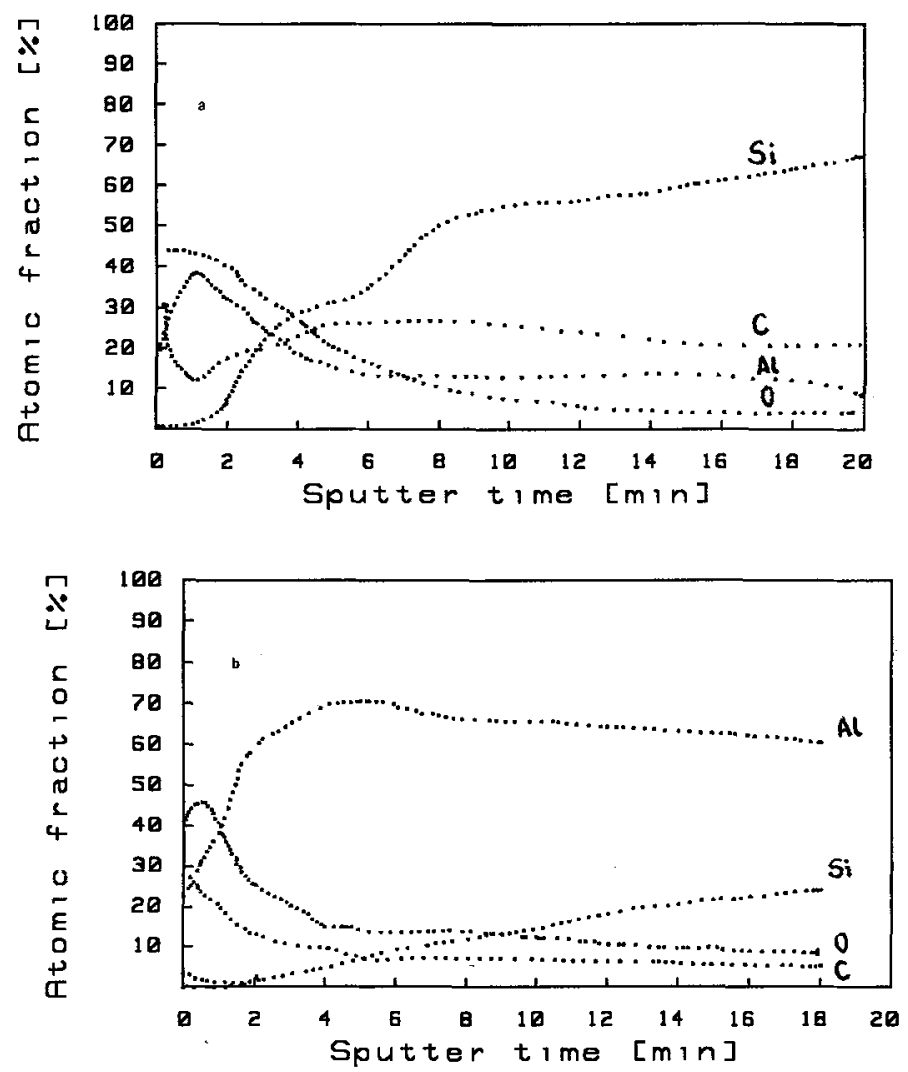

Fig.7 Auger electron intensity as a function of sputtering time

(a) Al stripe deposited from TMA $1 \mathrm{mbar}$, scanning speed $100 \mu \mathrm{m} / \mathrm{s}$, laser power $0.8 \mathrm{~W}$

(b) Al stripe deposited from TMAA $0.1 \mathrm{mbar}$, scanning speed $20 \mu \mathrm{m} / \mathrm{s}$, laser power $1.3 \mathrm{~W}$

The top layers of the films grown from both precursors exhibit the usual oxide coating which results from exposure to air prior to the analysis. The native $\mathrm{SiO}_{2}$ on the silicon substrate could contribute the oxygen contamination in depth as well. There are two possible reasons for silicon content. One could be background response from the wafer itself, and the other from solid solutions of silicon and aluminium formed during irradiation with pulsed visible laser. Aluminium stripes grown from TMAA in our experiments are thicker compared to those obtained from TMA. This determines the attenuation of the Auger signal from silicon substrate. When comparing aluminium and carbon contents presented on Fig.7 (a) and (b) one could realize the advantages of TMAA as aluminium precursor over TMA. The carbon contamination in the layer is considerably reduced due to the absence of direct $\mathrm{Al}-\mathrm{C}$ bond and easy cleavage of weakly coordinated Al-N bond. The decomposition mechanism of TMAA determines high aluminium content obtained by laser pyrolysis. Relatively high carbon contamination in LCVD written aluminium stripes using TMA and TMAA was probably due to the unconventional way of precursors decomposition caused by pulsed laser irradiation and secondary reactions of the products. It was confirmed by in situ mass spectrometric studies of gaseous phase composition during the deposition process [14,25]. Our results for elemental analysis of aluminium grown from TMAA differ from those reported by Baum et al. [12] who did not find carbon 
contamination in the laser deposited aluminium lines. This could be caused by the different nature of $\mathrm{cW} \mathrm{Ar}+$ laser used in this work compared to our light source - copper bromide vapor laser.

The resistivity of each stripe was calculated after evaluation of the geometric parameters and resistance. The lowest value obtained for TMA was $90 \mu \Omega . \mathrm{cm}$ and resistivity depended on the process parameters [13]. Use of TMAA as a precursor determined deposition of more pure aluminium stripes which resulted in lower resistivity. The calculated values for this precursor were consistently $1.5-3.5$ times that of bulk aluminium $(2.8 \mu \Omega . \mathrm{cm})$ and the lowest value reached was $4.0 \mu \Omega . \mathrm{cm}$. The resistivity was almost independent of the scanning speeds in the range of 10 $-60 \mu \mathrm{m} / \mathrm{s}$ where the best results were obtained. Similar resistivity behavior of laser deposited Al lines was reported by Baum et al. [12].

\section{Conclusions}

Comparative study of TMA and TMAA as precursors for LCVD of aluminium with pulsed visible laser was performed. Similar granular structure of aluminium stripes deposited from both precursors was obtained. The laser induced pyrolytic decomposition of TMAA yielded aluminium lines with lower contents of carbon and oxygen compared to that deposited from TMA. The difference in the layers composition for the used precursors resulted in their resistivity values. The low resistivities of aluminium stripes deposited from TMAA (up to 4.0 $\mu \Omega . \mathrm{cm})$ makes it preferable precursor for laser written interconnections in IC technology.

\section{Acknowledgements}

The authors are grateful to the Ministry of Science, Education and Culture for financial support under Project 177-X. We would also like to thank Dr. V.Dimitrov for synthesis and purification of the aluminium precursors used.

\section{References}

1. R.A.Levy, M.L.Green and P.K.Gellagher, J. Electrochem. Soc. 131 (1984) 2175

2. D.R.Biswas, C.Ghosh and R.L.Layman, J. Electrochem. Soc. 130 (1983) 234

3. T.F.Kuech, E.Veuhoff, T.S.Kuan, V.Deline and R.Potemski, J. Crystal Growth 77 (1986) 257

4. D.J.Ehrlich and J.Y.Tsao, J. Vac. Sci. Technol. B 1 (1983) 969

5. W.S.Hobson, T.D.Harris, C.R.Abernathy and S.J.Pearton, Appl. Phys. Lett. 58 (1991) 77

6. A.S.Grady, R.D.Markwell, D.K.Russell and A.C.Jones, J. Crystal Growth 106 (1990) 239

7. C.R.Abernathy, A.S.Jordan, S.J.Pearton, W.S.Hobson, D.A.Bohling and G.T.Muhr, Appl. Phys. Lett. 56 (1990) 2654

8. D.B.Beach, S.E.Blum and F.K.LeGoues, J. Vac. Sci. Technol. A 7 (1989) 3117

9. W.L.Gladfelter, D.C.Boyd and K.F.Jensen, Chemistry of Materials 1 (1989) 339

10. L.W.Dubois, B.R.Zegarski, C.Kao and R.G.Nuzzo, Surf. Sci. 236 (1990) 77

11. M.E.Gross, K.P.Cheung, C.G.Fleming, J.Kovalchick and L.A.Heimbrook, J. Vac. Sci. Technol. A 9 (1991) 57

12. T.H.Baum, C.E.Larson and R.L.Jackson, Appl. Phys. Lett. 55 (1989) 1264

13. V.Shanov, B.Ivanov and C.Popov, Thin Solid Films 207 (1992) 71

14. B.Ivanov, C.Popov and V.Shanov, Advanced Materials for Optics and Electronics $1(1992) 287$

15. V.Shanov, C.Popov, B.Ivanov, A.Souleva and G.Peev, J. Materials Science: Materials for Electronics 4 (1993) 55

16. V.Shanov, B.Ivanov and C.Popov, Processing of Advanced Materials 3 (1992) 41

17. G.W.Fraser, N.N.Greenwood and B.P.Straughan, J. Chem. Soc. (1963) 3742

18. J.K.Ruff, Inorg. Synth. 9 (1967) 30

19. J.K.Ruff and M.F.Hawthorne, J. Am. Chem. Soc. 82 (1960) 2141

20. Y.I.Nissim, A.Lietoila, R.B.Gold and J.F.Gibbons, J. Appl. Phys. 51 (1980) 274

21. D.Bauerle "Chemical Processing with Lasers", Springer-Verlag, Heidelberg, 1986, p.57

22. Y.Rytz-Froidevaux and R.P.Salathe, Proc. Soc. Photo - Opt. Instrum. Eng. 469 (1984) 55

23. C.Garrido-Suarez, D.Broichotte and H. van den Bergh, Appl. Phys. A 46 (1988) 285

24. C.R.Moylan, T.H.Baum and C.R.Jones, Appl. Phys. A 40 (1986) 1

25. C.Popov, B.Ivanov and V.Shanov - in preparation 